\title{
Hospitality, Russian style: nine communication challenges
}

By: Dianne H.B. Welsh and Skip Swerdlow.

Welsh, D.H.B., \& Swerdlow, S. (1992, December). Hospitality Russian style: Nine communication challenges. Cornell Hotel and Restaurant Administration Quarterly, 33(6), 64-72.

\section{***Note: Figures may be missing from this format of the document}

\begin{abstract}
:
The former Soviet Union remains an attractive investment alternative for Western managers. However, the flow of Western investments may be impeded by the problems of intercultural communication which may result in misunderstanding and costly inefficiencies. Nine intercultural considerations are discussed. These areas include negotiations, communication channels, group dynamics, education, language, barriers, new ideas, training, culture and misinterpretation. Western manager must make allowances for the fact that Western concepts of management are just being introduced in the former USSR.
\end{abstract}

\section{Article:}

As a market that has been closed for over 70 years, the former U.S.S.R. represents an exceptional business opportunity--but there are risks, too, given the political and economic uncertainties inherent in today's Russian culture despite the uncertain economic and political systems that are the remnants of the former Soviet Union, large Western businesses continue to be interested in that immense and potentially lucrative market. Although international business development has slowed in the last year due to differences between the central government and the republics and because of the uncertain futures facing the states of the former Soviet Union, the flow of aid and international joint-venture (IJV) opportunities will likely increase under President Boris Yeltsin's leadership. Yeltsin believes that Russia and the other republics cannot succeed without it.

Western hospitality companies are among the businesses hoping to find new and profitable markets within the former Soviet states. Indeed, some food-service and lodging firms already have established good working relationships in Russian cities. Entering Russian business markets, however, is not always an easy proposition. Differences in culture, language, and motivation must be considered. In this article we introduce some of the dynamics of communication that may affect interactions with business leaders in the former Soviet states. In so doing, it is necessary to use broad and sweeping generalizations that may not apply to all individuals but that nevertheless describe segments of the Russian population and point to potential areas of misunderstanding. It is our belief that individuals cannot and should not be stereotyped. By being aware of what pitfalls may exist, however, Western business leaders will be able to recognize quickly what sources of confusion and misinterpretation are present in any given situation.

Background. Yeltsin's visit to the United States last year, when he met with President Bush, congressional leaders, and U.S. business executives, was designed to create an investment package to aid the Soviet Republics in the following areas: employee training, food-storage 
facilities, conversion of defense industries to civilian use, and banking.(1) Such an agreement aims to enhance economic and political cooperation between the republics wishing to belong to a new Commonwealth of Independent States.

The 72-hour coup of August 1991 is a stunning example of the instability occurring throughout the republics of the former Soviet Union. And it will continue to be an unstable period in the future, warns Louise Shelly, a professor at American University.(2) Because the reform process is likely to take sometime, it should be looked on as a renewal of faith in reform itself, rather than as a total conversion by the Russian people.

Even the demonstrations for democracy and personal freedom in Moscow, Leningrad, and elsewhere--while informed by Western capitalistic practices--were not necessarily inspired by them.(3) Yeltsin, an advocate of strong capitalistic practices, was hailed a hero, while communism was declared a casualty. He is clearly the center of gravity in Russian politics. Around the world, the result of the coup was (and is) hope and optimism, and foreign business investments in Russia will take on a renewed interest.

Perestroika and glasnost are now more than seven years old, and are indelibly part of the Russian economy and political system. The new order will push even harder for reform. The republics, which face many imminent shortages of goods, need the West to save their economies and to help them implement a market-regulated economy.

\section{Hospitality, Russian Style}

During the past three years, the U.S. hospitality industry has begun making inroads into the Russian economy. Both McDonald's and Pizza Hut have opened successful restaurants in large cities. Radisson, Finnair, and Sheraton have opened or are in the process of opening hotels. Marriott has begun serving meals on Aeroflot, the government-owned airline, and other big hospitality companies are investigating various possibilities for expansion.

The potential of the Russian hospitality market, both foreign and domestic, is just being recognized. East-West business summits and trade shows are becoming common, and many of these are specifically targeting hotel and restaurant businesses. Russian educational institutions are beginning to include hospitality courses in the curriculum.

A decision to open a hotel or restaurant in Russia is a formidable and expensive one. The challenge is more than finding sources of supply, negotiating with bureaucrats, and dealing with the inconvertibility of the ruble, to name a few obstacles. Those tasks can be accomplished through a comprehensive business plan, perseverance, and good intentions. The whole process of intercultural communication, however, presents what may be the biggest challenge for American management. Face-to-face communication in Russia must be examined so that misunderstandings, conflict, and costly inefficiency can be avoided, thereby allowing awareness and adaptation to prevail.

\section{Communication}

The authors have identified nine communication challenges--that is, intercultural considerations-for hospitality managers hoping to do business in any of the former Soviet states. The first seven 
of these have a major impact upon communication between the East and the West. The latter two are of less importance because they apply to specific situations. All nine are described in detail, with recommendations to hospitality executives and managers.

Common ground. Those in the hospitality field must understand the following background information to communicate effectively with Russians:

(1) The deeply rooted Russian culture is based on strong historical and political foundations that are considerably different from those of the West.(4)

(2) Perestroika and glasnost have cultivated a new vocabulary for many Russians--words such as democracy, capitalism, management, and human relations, to name a few. Such words may or may not have the same meaning as in the West, and some business and economics terminology, for example, may have no meaning at all.(5)

(3) Western management theory and business practices are relatively new to the Russians. Only in the last few years have schools of management and marketing appeared, and these train only a small number of selected students. The education system's closest equivalent until recently has been traditional Marxist-Leninist economics.

Since the early days of perestroika, tourists have experienced less-than-hospitable conditions, relative to Western standards. Intourist, the official travel agency, is a prime example of a system that needs to add more customer service.(6)

\section{Background of the Study}

The information presented here comes primarily through observations made during two trips to Russia encompassing 14 weeks, and a yearlong contact period prior to and since the trips, in 1989 and 1990. Daily interactions occurred with Russian grade-school, high-school, and university students; faculty and administrators; and factory workers, managers, bureaucrats, and common citizens. The issues described in this paper are based on personal observations and encounters.(7)

\section{Nine Communication Challenges}

The nine communication challenges that we outline in detail have to do with these concepts: (1) negotiations, (2) communication channels, (3) group dynamics, (4) education, (5) language barriers, (6) new ideas, (7) training, (8) culture, and (9) misinterpretations.

Negotiations. Russians are known to be hard bargainers, and negotiations may last longer than those to which Westerners are accustomed. It is advantageous to be well prepared and be willing to explain your stance. Present facts and figures to back up your decisions. Expect a relatively long time line. Both sides will probably have to explain their stance in great detail.

The art of detailed negotiating has for generations been part of the culture of the Slavic-Teutonic people. In terms of the hospitality industry, the characteristics underlying Russians' perspectives on negotiations have the following implications: 
* Negotiations are lengthy and complicated by ever-changing state regulations. The current economic and political uncertainty creates additional confusion. Diligence and patience, therefore, are virtues.

* Respect in negotiations is attained through determination, perseverance, and compromise. This is taught in the schools starting at an early age, as is the value of hard work. Students, from grade school on, are channeled into particular areas of study based on their individual achievements. Students' futures are based on excelling in these chosen areas of study. These characteristics commit them to their belief systems and to what they feel is important. Persistence and patience, therefore, are essential when negotiating with Russians.

Communication channels. Russians have a great thirst for information, perhaps because of their lack of access to it during the cold-war period. This quest for knowledge is both at the root of and a result of glasnost. Information in Russia is more accessible now than it has ever been. The town square of any major former-Soviet city is now a gathering place where citizens may talk freely, as they often do until well past the midnight hour. The Russian people's intense curiosity leads to their tendency to dominate conversations, leaving little time for Western visitors to ask questions. Russian citizens commonly stop easy-to-spot Westerners on the street to ask about Western life and life-styles. Visitors to Russia should plan to allow time for such interruptions. Another limitation is that visitors to former Soviet states are on a strict timetable because their visa authorization is limited. Although visas can be extended, the procedure is complicated and time-consuming, requiring an adherence to the original schedule.

Open communication channels are essential. Trust is best established through direct, one-on-one communications. Hospitality executives should be prepared to make numerous trips to Russia. They should arrive with a list of topics for discussion and particular questions that need to be addressed during the visit. Sufficient time should be allowed for an equal exchange of questions and concerns.

Group dynamics. Russians are apt to be less verbal in a group than their Western counterparts. Although they will participate in consensus building, their involvement usually comes toward the completion of the process. Generally, they are more open in one-on-one discussions and meetings.

An exception to this observation is when the group is relatively small, say, fewer than ten people, and has a long-standing working relationship. Discussion in such groups tends to open up and be productive quickly, regardless of the topic.

Hospitality managers are encouraged not to try to speed up this process. From an operations perspective, time should be allotted in the daily schedule for this process to take its course. For example, imagine you're a manager trying to resolve a rooms-related problem. Scheduling an allemployee meeting may lead to a discussion of how to solve that particular operational problem, but the resulting group consensus may differ from the individual opinions of the majority of the workers. You would not learn that, however, by rushing right to the group-meeting stage. Taking the time to meet with employees in small groups and one-on-one, and being patient until the group consensus is established, yields more-productive results. 
Business and hospitality education. "Profit," "income statement," "balance sheet," "cash flow," and many other basic business concepts are relatively new to Russians because their financial system is just now being transformed into a market economy. This difference in basic knowledge and familiarity with free-market ideas may represent one of the biggest challenges to the hospitality specialist.

Since few hospitality or business-administration schools currently exist in the former Soviet Union, such educational institutions need to be formed now, to introduce more students to business curricula and to present additional career avenues to these individuals, thereby helping meet the industry's future human-resource needs. In the absence of such schooling, Russian youth--who represent the pool of potential employees in hotels or restaurants--might question their qualifications as effective workers or job candidates because of their lack of career training.

In part because of the historic difference in economic systems, expectations of performance should be realistic, and attempts to enhance performance must be accompanied by training and education. It's important that Western managers not make assumptions and that they listen to their Russian counterparts and to Russian workers to determine what education is relevant. The learning process needs to be interactive, and both sides must be flexible enough to learn from each other. Consider this simple example: Beds in Russia are typically lower than beds in the West. This may require Western hotel operators doing business in the former Soviet states to adopt the Russian practice of neatly tucking in the bedspread with the sheets. On the other hand, a profit-and-loss forecast is a necessity, and as such its purpose, development, and use must be taught to Russian managers.

Language barriers. Accurate translation of documents is important, since many Russian managers and other employees read only Russian. Three primary difficulties that may be encountered are: (1) there are few Russian translators in the West (relative to those able to translate from English into Spanish, French, and German); (2) although Russian translators as a group are well trained by academic standards, they have less of a feel for concepts and idioms that are indigenous to the West (in part because their exposure to and experience with Westerners was limited by travel restrictions prior to the 1970s); and (3) differences exist in how words, phrases, and interpretations should be translated, even among Russian experts.

All materials should be prepared in English as well as Russian, including training manuals, policies and procedures, marketing plans, and other documents. The following suggestions are made to help ensure that any translation achieves its objectives.

* Have Russian and Western translators work together, so that both may contribute their cultural and technical expertise. Cross-validation should be done by at least two other translators. While this may seem expensive and time-consuming, in the long run the benefits will be obvious. * The author(s) of the documents should play an active role in the translation. It should be an interactive process to ensure that the integrity of the original meaning is maintained.

* Follow up to ensure that the entire translation process is being carried out in the agreed-upon manner. 
To translate surveys that were to be administered in Russia, we followed a three-step process. First, a college-educated, English-speaking Russian with U.S. citizenship did the initial translation. Next, the first translation was validated by another Russian who is a specialist in international joint ventures. Finally, a professor of Russian checked for problems with interpretation.

During this process we encountered not only words that had several different meanings (e.g., "hot" could refer to temperature or temperament), but also concepts that had no practical Russian equivalent (e.g., "franchising" and "profit"). Throughout this process the translation changed greatly. Even so, the final translation was not without flaws--students still required oral explanations to complete the survey's questions.

New ideas. The Russian people are great "adapters." Their willingness and ability to be flexible have come from years of dealing with shortages and a highly bureaucratic system. This characteristic is a strength waiting to be tapped. Russian managers and workers, then, are able not only to adapt quickly to Western-management styles, but also to make individual contributions and suggestions for improving operations when it's clear such feedback is welcome.

Training. Western training programs for Russian operations may include adapting methods and practices to what will work in Russia. One must not assume that Western business leaders know everything and the Russians know nothing. On the contrary, the Russians are skillful business people, particularly on the "input" side of the equation, such as their ability to acquire goods. Constantly dealing with shortages and delays in shipping of almost everything has made them creative, resourceful, and industrious in meeting such challenges. Westerners, in general, are better prepared to deal with the "output" aspects of business, such as marketing products. 8 Russian managers will need training in human-resource management, particularly skills related to the effective use of feedback and the use of nonfinancial incentive systems, such as contingent time off.(9)

Russian managers will benefit from being able to observe firsthand how service, operations, and general management are executed in Western-style hospitality enterprises. While such trips for training purposes should be encouraged, it's still necessary to make clear from the outset that the intent of all employees must be to remain citizens of Russia. Also, the timetables for departure and return must be made clear in advance.

The learning process will be greatly enhanced if the Russian travelers speak English, although accommodation can be made. Because fluency in the destination country's language is considered a plus when applying for an exit visa, Western companies that form partnerships with Russian businesses may find it beneficial to sponsor language classes for their Russian employees to facilitate training.

Culture. Because Russians and Americans (for example) are accustomed to seeing and wearing different styles of clothing, some adaptations are important. For instance, hotel and restaurant employees in customer-contact positions will need uniforms and a dress code. Providing uniforms will improve morale and make guests feel more comfortable. Management will have to 
provide the outfits because the cost of clothing in Russia is prohibitive. For example, consider that a simple summer dress cost an Intourist travel guide two-thirds of her monthly salary in 1990.

Misinterpretations. The concepts of perestroika and glasnost are much better understood in the West, where they have been publicized in detail for several years, than they are almost anywhere in Russia. In terms of planning and operating a hospitality property--as well as many other types of businesses--the laws governing the operation of a foreign-owned subsidiary are constantly changing. A number of law firms specializing in joint ventures are now located in Moscow and Washington, D.C. Retaining such a firm is urged because of the changing environment. Access to up-to-date legal, political, and economic expertise is a necessity.

Daily operations also need to be monitored to ensure that current legal requirements are being met. For example, a Russian manager may neglect to apply for a license to serve liquor, assuming it is no longer necessary under perestroika. Executives, therefore, should not rely on their working managers as the only source of information. It's likely that managers will be unaware of the correct or most recent procedures. Hospitality executives should take responsibility for remaining current with applicable laws and regulations and passing that information along to all managers and employees so as to avert miscommunication.

\section{Risks and Rewards}

Entering the Russian marketplace can be a major risk for a hospitality concern. At times the process will seem arduous and even onerous. On the other hand, penetrating a market that has essentially been closed for over 70 years is an exceptional opportunity. The risks arise from a history of political and economic uncertainty inherent in the Russian culture, while the opportunities come from the hopeful but questionable future that Russia and the other former Soviet states now face. To overcome the risks and be prepared to grasp the opportunities requires an intelligent and sensitive integration with Russian culture and business practices.

\section{Observations from a Recent Visit to the CIS}

In September 1992 I spent 15 days in the Russian and Ukrainian republics of the Commonwealth of Independent States (CIS). I visited or stayed in 11 hotels and experienced even more restaurants, interviewing managers and staff members, touring facilities, and surveying employees' attitudes about a variety of issues. The most important observation, I believe, is that movement to a market economy in the CIS really is occurring, albeit at different rates in different sectors of the economy. I saw and experienced evidence that the hospitality industry--hotels, restaurants, tour and travel services, among others--is at the vanguard of this change, perhaps more so than any other industry in this part of the world.

Changes in hospitality operations. Three years ago, reports of hospitality service in the U.S.S.R. consistently indicated that employees were rude, procedures were cumbersome and inconsiderate of guests, and standards of cleanliness and service were poor. Travel in the Soviet Union was unpleasant. More than 70 years of state economic planning and government suppression of individual expression made service as we know it alien to the average Russian. But changes are now taking place that will benefit visitors. Here are some examples. 
Walk into a typical tourist hotel in any major city in the CIS and you will find a conveniently placed front desk with smiling employees ready to check you in. They may not speak English, which is a common challenge everywhere in the Commonwealth, but they will quickly find someone who does. Legal procedures from pre-perestroika days, however, continue to mix with the transition. For example, you must surrender your passport until you check out, and it will not be returned until the hotel retrieves your room key. Most of the hotels have "floor ladies," individuals placed on each floor who have many of the responsibilities of a typical conciergefloor butler. They hold your room key, arrange for laundry, give wake-up calls, and politely greet you.

Almost all the hotels had shops that sold souvenirs for hard currency and rubles. The Yalta Hotel, overlooking the Baltic Sea, had numerous independent concessions. I saw orange juicers, Reebok tennis shoes, and Levi shirts, all selling for less than in the United States. Traditional Russian items for sale were generally of good quality and priced competitively. Several hotels had casinos boasting Las Vegas-type gaming activity, and all had post offices (mail takes two to five weeks to reach the United States).

Managers are beginning to use real incentives to get people to take pride in a job well done. Prior to perestroika, they gave only "moral incentives," a pat on the back or a plaque on display. Economic conditions and a better understanding of motivational options have allowed most hotels to offer money rewards. Some general managers, such as Victory I. Baryshev at the Hotel Intourist in Moscow and Gennady V. Timoschenko at the Hotel St. Petersburg, have sent top employees, including housekeepers and wait staff, to Europe and the United States for training and on-site visitations, with incredible success.

Reasons for leadership. The most obvious influence is that Westerners, regardless of their reasons for traveling to the CIS, need to use hospitality facilities when they arrive. They stay in hotels and eat in restaurants, and it's expected that they'll come back to the properties that do the best job and feel the most familiar. The hotels in which I stayed were frequented primarily by visitors from the United States, Europe, and Pacific Asia, a mixture of business and pleasure travelers. Even the suburban properties look to Western business to raise occupancies. Giorgi G. Risanko, deputy director of the Tourist Hotel in Tver, Russia, is developing marketing promotions directed at non-Russian travelers. When I asked Yuri A. Tichonov, director of the Volga Hotel in Tver, if he was going to try to attract "foreigners" from the other Commonwealth republics, a look of shock washed across his face--no one had yet referred to the citizens of his neighboring republics as anything other than fellow Soviets. He reluctantly replied, "I guess we will have to."

Western business also means hard currency, which is more highly valued and stable than the ruble. Hard currency means a reliable income that can be reinvested, and managers recognize that it can only be attracted consistently if they satisfy the guest. "My highest priority is the guest, and only good employees will make the guests come back," said Baryshev, who also stated that he has been able to make more changes to the hotel because he makes and keeps its profit. His comments could easily have passed for those of a Western general manager. The hospitality business encourages capitalistic behavior because its successful application shows immediate results. Employees get tips when they are customer-oriented, and guests 
otherwise express their satisfaction or displeasure with the service. Vyacheslav K. Khrustalev, deputy general manager of the Salout Hotel in Moscow, showed me the customer-comment cards he uses to assess his employees' performance. The Yalta Hotel and Hotel Intourist also solicit customer feedback.

Now what? The government is no longer in control of how business is run in the republics, and it does not prop up those that are in trouble. Mikhail B. Lesin, technical manager (i.e., engineering manager) of the Hotel St. Petersburg, was representative of managers throughout the country in expressing his hopefulness about, and frustration with, their newfound freedom. Managers are in total control of their properties, but they also want direction. They are getting it from their customers, and they are listening. But the political system is silent and in disarray. They receive no guidance from government, yet many antiquated laws are still on the books. For example, one such law forbids Russian citizens from staying in hotels in their home town, a holdover from the days of Stalin. Many of the laws are ignored, but making a decision about which ones to discount is confusing. To deal with those issues, managers are beginning to form and join associations for purposes of solving joint problems and lobbying the government.

Some are quite active, for example, the leaders of local hotel associations, but others have difficulty seeing the benefit of such organizations, complaining that they either do not know who to contact to express their opinions or are afraid of any group that is a force for change.

The result is that the hospitality industry of Russia is looking more and more like that of the West. All the hotels that I visited had the feel of Western budget-type properties, or better. Some needed renovation and repairs, but the warmth of the Russian people made up for any physical defects. Employees seem to be gaining a previously unreported enthusiasm for their jobs. And the guests with whom I spoke expressed satisfaction with the service. Still, a key to visiting the republics is to discard or lower one's Western expectations, and to leave oneself open for adventure. I was always pleasantly surprised--sometimes embarrassed, even--when I got more than I expected.

Great potential. The challenge that the industry faces is to maintain patience throughout the difficult transition period to a market economy. The people are frustrated with the snail's pace of change and the suffering that they must endure. To a person, however, none wished to go back to communism and an oppressive, state-controlled society. Most seemed to want some strong leadership, however, to fill the vacuum that they feel exists.

The people in the CIS have an inherent Slavic sense of hospitality that has a family feel to it. Once they know foreigners well enough to trust them, they enthusiastically offer whatever they can to make them feel more comfortable. I experienced this during the family visits that were part of my tour. Those visits left me with many new good friends--wonderful people whom I wish to visit again next year. I was also fortunate enough to make connections with the managers of many of the hotels that I toured. They presented their property proudly, provided information, and introduced me to their people.

The hospitality industry in the CIS stands at the brink of a great opportunity to demonstrate how the application of market principles works for employees, guests, and management. A blend of Western technology and investment with Slavic warmth and hospitality is destined to succeed. 


\section{NOTES}

Dianne H.B. Welsh, Ph.D., is an assistant professor of management at Eastern Washington University. Skip Swerdlow, Ph.D., is an associate professor of hotel management at the University of Nevada at Las Vegas. The authors thank the faculty and staff of Tver State University (Russia) for their assistance, particularly the members of the departments of economics and foreign languages.

\section{REFERENCES}

1 Gerald Seib, "Yeltsin Meets with Bush and Gets Offer of Limited Help for Russian Republic," Wall Street Journal, 124, No. 121 (June 21, 1991), p. B2.

2 B. Dart, "Americans Feel Good about It All," The Spokesman Review, 109, No. 69 (August 22, 1991), p. A6.

3 G. Blonston, "Failed Coup Thrusts Hard-Liners into the Past," The Spokesman Review, 109, No. 69 (August 22, 1991), p. A6.

4 See: Andrea Rutherford, "Soviet Students Learn Some New Lessons," Wall Street Journal February 26, 1991, p. A10; Anthony DePalma, "Giving Soviets a Lesson in Thinking," New York Times, 140, January 30, 1991, p. B7; and Oded Shenkar and Yoram Zeira, "International Joint Ventures: A Tough Test for HR," Personnel, January 1990, pp. 26-31.

5 Alexander Ardishvilli, "Management Training in the U.S.S.R. and Gorbachev's Perestroika," a paper presented at the Decision Sciences Institute Meeting, New Orleans, November 1989.

6 See: Allen R. Myerson, "Suddenly, the Specter of Capitalism Is Haunting Intourist," New York Times, 140, November 18, 1990, p. F4; Petrer Gumbel, "Opening of Soviet McDonald's Is Wellattended," Wall Street Journal, February 1, 1990, p. A10; and, for a complete review, Dianne H.B. Welsh, "The Early Days of Perestroika: First-Hand Impressions," in F. Luthan and R.M. Hodgetts, International Management (New York: McGraw-Hill, 1991).

7 This research was partially funded by grants from the Northwest Institute of Advanced Studies (NWIAS) and the Eastern Washington University (EWU) Foundation.

8 Paul Lawrence and Charalambos A. Vlachoutisicos, Behind the Factory Walls: Decision Making in Soviet and U.S. Enterprises (Boston: Harvard Business School Press, 1990), p. 295. 9 While in Russia, coauthor Welsh advised the manager of a retail store to let employees off two hours early with pay on any day that they agreed to vend on the street for four hours. The manager experimented with the suggestion and, as a result, the store's sales rose dramatically and employee morale improved. (See: Dianne H.B. Welsh, Nancy Birch, and Fred Luthans, "Contingent Reinforcement in the U.S.S.R.: An Empirical Study of Salespersons' Performance Behavior," Proceedings of the Decision Science Institute, Miami Beach, November 1991, p. 233.) 